\title{
Use Opportunities of Some Natural Herbaceous Plants of Cankiri Province in Landscape Applications
}

\author{
Gamze Tuttu (Corresponding author) \\ Cankiri Karatekin University, Faculty of Forestry, \\ Department of Forest Engineering, 18200, Cankiri, Turkey \\ E-mail: gamze.tuttu@gmail.com \\ Ibrahim Aytas \\ Cankiri Karatekin University, Faculty of Forestry, \\ Department of Landscape Architecture, 18200, Cankiri, Turkey \\ E-mail: aytasibrahim@karatekin.edu.tr \\ Zuhal Dilaver \\ Ankara University, Faculty of Agriculture, \\ Department of Landscape Architecture, Ankara, Turkey \\ E-mail: dilaver@agri.ankara.edu.tr
}

\begin{abstract}
In landscape arrangements, selection of plant species which have high value as ecological, aesthetic, functional and economically is important. That is one of the main subjects that increase the quality of natural and cultural landscape. Preference of natural herbs which growth in local region and adapted to environmental conditions contributes both rural-urban connectivity and urban biodiversity. It also reduces the pressure of urban structures on natural habitats. According to Flora of Turkey, 358 taxa has been recorded in Çankırı province. The aim of this study is to determine the landscape characteristics and use opportunities of the herbaceous species in Çankırı flora, in addition to this, to protect sensitive species that are high ecological value in the region. Besides, it promotes the production of natural plants as ornamental. As a result, 22 natural herb have been considered suitable for landscape applications.
\end{abstract}

Keywords: Çankırı, herbaceous plant, natural landscape, landscape usage

DOI: $10.7176 / \mathrm{JSTR} / 5-3-16$

\section{Çankırı İlinin Doğal Bazı Otsu Bitkilerinin Peyzaj Uygulamalarında Kullanım Olanakları}

\begin{abstract}
Özet
Peyzaj düzenlemelerinde ekolojik, estetik, işlevsel ve ekonomik olarak yüksek değere sahip bitki tür seçimine önem verilmesi, doğal ve kültürel peyzajın kalitesini artıran temel konuların başında gelmektedir. Yöreye özgü ve çevre koşullarına adaptasyonunu tamamlamış doğal bitki türlerinin tercih edilmesi hem kır-kent bütünlügüne ve kentsel biyoçeşitliliğe katkılar sunmakta hem de kentsel yapıların doğal habitatlara olan baskısını azaltmaktadır. Türkiye florasına göre Çankırı ilinde kayıtlı toplam 358 takson bulunmaktadır. Bu çalışmanın amacı; Çankırı florasındaki otsu türlerin peyzaj özellikleri ve peyzajda kullanım olanaklarını tespit ederek bölgedeki ekolojik değeri yüksek olan hassas türlerin korunmasının yanında süs bitkileri bazında üretimlerinin de artırılmasına katkıda bulunmaktır. Çalışma kapsamında peyzaj uygulamalarında 22 doğal otsu bitki türünün kullanımı uygun görülmüş olup, bu türlerin kullanım olanakları irdelenmiştir.
\end{abstract}

Anahtar Kelimeler: Çankırı, Otsu bitki, Doğal peyzaj, Peyzaj kullanımı 


\section{Giriş}

Hızlı nüfus artışı ve çarpık kentleşme anlayışı doğal ortamlara olan baskıyı giderek artırmaktadır. Eski çağlardan günümüze kadar olan süreçte doğal alanlar üzerindeki tüm antropojenik faaliyetler, bu alanlardaki mevcut bitki örtüsü ile potansiyel (ideal) bitki örtüsü arasında onarılamaz derecede büyük farklara yol açmıştır (Altan, 2000). Kentsel peyzaj düzenlemelerinde, yöreye özgü ve çevre koşullarına adaptasyon sorunu olmayan doğal bitki türlerinin tercih edilmesi, bitki örtüsündeki bozulmaların onarılması ya da minimum seviyeye indirilmesine katkı sağlar. Doğal türlerin bulundukları bölgenin toprak, su, iklim gibi faktörlere iyi bir şekilde adapte olabilme özellikleri, kırsal ve kentsel peyzaj uygulamalarında kullanıcı ve uygulayıcılara büyük avantajlar sağlamanın yanında peyzaj uygulamalarının başarısını da artırır (Cengiz, 2001; Yazgan vd., 2005). Ayrıca, kentsel mekânlardaki doğal tür uygulamaları, kent ekosistemine ve kentsel biyoçeşitliliğe önemli ölçüde katkı sağlamaktadır.

Doğal türlerin peyzajda süs bitkisi olarak kullanılması ekolojik, ekonomik ve estetik birçok faydayı da beraberinde getirmektedir. Doğal türlerin ekolojik açıdan biyoçeşitliliğin korunmasına yardımcı olması, yaban hayatı bakımından türler için habitat sağlaması ve ideal bir çevre sunması, ekonomik olarak egzotik türlere oranla işgücünü ve bakım masraflarını azaltması gibi çok yönlü birtakım yararları vardır (Dilaver, 2001; 2014). Dünya Koruma Birliği (IUCN, 2013) tarafından doğal vejetasyonun yok olarak istilacı türlerin yaygınlaşması, kentsel biyoçeşitliliği negatif yönde etkileyen faktörler arasında değerlendirilmiştir. Uluslararası bazı bilimsel çalışmalar (Chan et.al., 2014; Beninde et.al., 2015) ise; kentlerdeki doğal yeşil alan oranlarındaki artışın ve doğal bitki türü bazındaki artışın kentsel biyoçeşitliliği de artırdığını göstermiştir. Ayrıca, kentsel alanlarda doğal tür kullanımı yoluyla kentlerdeki çevre kalitesi yanında yapı kitleleri ile doğal ortamlar arasında hem tampon oluşturularak hem de geçiş sağlanarak görsel peyzaj kalitesi de artırılabilmektedir (Barış, 2002; Yazgan vd., 2005; Özyavuz, 2011). Tüm bu değerlendirmelerden yola çıkılarak, Çankırı doğal bitki örtüsündeki otsu türlerin kent peyzajına entegrasyonunu sağlamak ve kentsel biyoçeşitliliğin zenginleştirilmesine katkıda bulunmak amacıyla ele alınan bu çalışmada, türlerin peyzaj uygulamalarında kullanım olanakları irdelenmiştir.

Çalışma alanının jipsli toprak yapısının bitki tür zenginliğine olanak sağlaması ve özellikle endemik türlerin önemli peyzaj değeri içermesi, alan belirlemede etkili olmuştur. Bu çalışmanın amacı; Çankırı florasındaki otsu türlerin özellikleri ve peyzajda kullanım olanaklarının belirlenmesi ile doğal türler konusunda farkındalık yaratmak, kullanımı konusunda talep oluşturmak ve Çankırı çevresindeki hassas türlerin korunmasını sağlamaktır. Doğal türlerin peyzaj mimarlığının çeşitli alanlarında kullanım olanaklarının arttırılmasının, korumacı yaklaşımla örtüştüğü ve bitkilerin yok olmasının önlenmesinde önemli katkı sağlayacağı düşünülmektedir.

\section{Materyal ve Yöntem}

Çankırı ilindeki doğal otsu bitkiler araştırmanın ana materyalini oluşturmaktadır. Türkiye florasına göre Çankırı ilinde toplam 358 takson bulunmaktadır (Davis, 1965-1985). Ele alınan bu taksonların içerisinden coğrafyaya özgü önemli peyzaj değerine sahip otsu bitki türleri tespit edilmiştir. Peyzaj uygulamalarında kullanılacak olan otsu bitkilerin seçiminde yörede yapılmış olan flora çalışmaları (Davis, 1965-1988; Tuttu ve Akkemik, 2017) temel alınmış olup endemizm, nesli tehlike altında olma durumları ile birlikte bitkinin form/habitus özelliği (Acar, 1997) ve renk (çiçek, yaprak, meyve) (Booth, 1990) bakımından yüksek estetik değere sahip olma kriteri dikkate alınmış, seçilen otsu türlerin habitat özellikleri (Davis, 1965-1988; Tuttu ve Akkemik, 2017) değerlendirilmiştir. Ayrıca türlerin botanik özelliklerinin tespitinde Flora of Turkey and the East Aegean Islands Vol. 1-9 (Davis 1965-1985), Türkçe adlarının tespitinde Türkiye Bitkileri Listesi (Güner vd., 2012) ve bitkilerin güncel isimleriyle otörlerinin belirlenmesinde (theplantlist.org-2019) internet sitesinden faydalanılmıştır.

\subsection{Araştırma Alanı}

Araştırma alanı, Karadeniz ikliminden İç Anadolu Bölgesine özgü kara iklimine geçiş kuşağında yer alan Çankırı ilidir (Şekil 1). Yapılan bir çalışmada (Gökmen, 2007), Çankırı'nın yarı kurak bir iklim kuşağında olduğu ve ilin doğal bitki örtüsünü steplerin oluşturduğu ifade edilmiştir. İran-Turan (İç Anadolu) Flora Bölgesi'nin etkisi altında bulunan Çankırı ili Davis'in kareleme sistemine göre A4 karesinde yer almaktadır (Davis 1965). Hemen hemen her mevsim yağışın görüldüğü ilde ortalama yıllık yağış miktarı $392-538$ kg/m2 arasında değişmektedir (Anonim, 2010). 


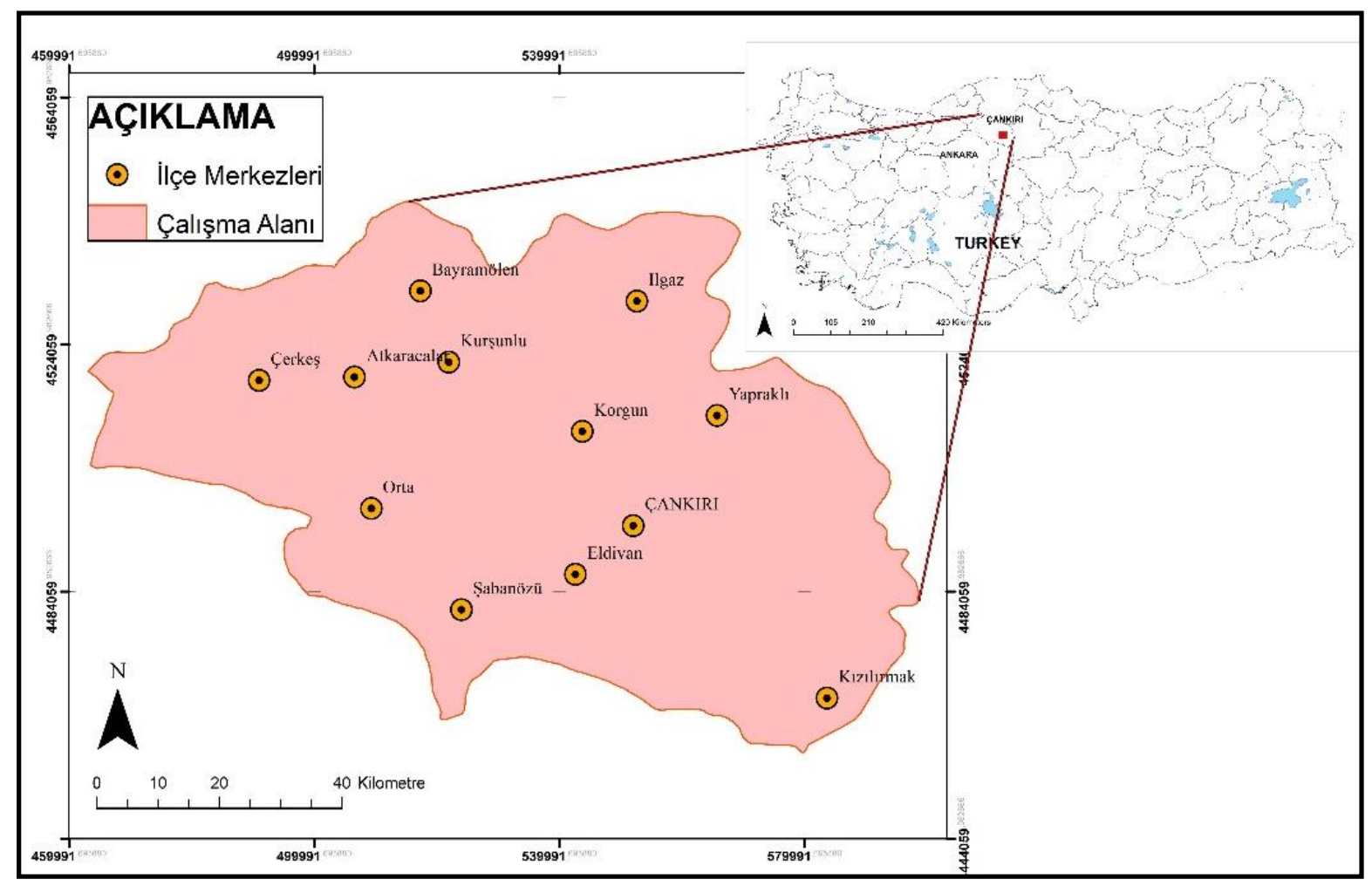

Şekil 1. Çalışma Alanının Konumu ve Sınırları

Çankırı genelinde arazilerde ormansızlaşma, tarım arazilerinin yerleşim amaçlı kullanımı, topraklarda aşırı tuzluluk ve jipsli yapı, şiddetli erozyon, bilinçsiz kullanıma dayalı bitki örtüsünde fakirleşme ve toprakta çoraklaşma gibi birçok olumsuzluğun yaşandığı bilinmektedir (Gökmen, 2007; Tuna, 2010). Özellikle kent merkezinin doğu ve güneydoğusundaki kaya tuzu rezervi bakımından zengin tepeler, aşırı tuzluluk nedeniyle çıplak bir görünüm kazanmıştır (Anonim, 2010; Tuna, 2010). Bunun yanında, alandaki jipsli kayaçlardan meydana gelen hâkim toprak yapısı, bitkilerin toprağa tutunma ve köklenme başarısını oldukça düşürmektedir (Doğan, 2002). Jipsin acı karakteri nedeniyle bitkiler için uygun bir yetişme ortamı oluşturmaması, bölgenin şiddetli sel ve erozyonlara maruz kalmasına neden olmaktadır (Gökmen, 2007).

\section{Bulgular ve Tartışma}

Yapılan literatür taramaları, arazi çalışmaları ve gözlemler sonucunda Çankırı'da doğal olarak bulunan, morfolojik, estetik ve ekolojik özellikler bakımından yüksek peyzaj değerine sahip 22 otsu bitki türü belirlenmiş̧tir (Şekil 2, Şekil 3). Tespit edilen türlerin botanik özellikleri (familyaları, latince-türkçe adları, endemizm ve tehlike durumları ile fitocoğrafik bölgeleri) Tablo 1'de; boyları, form/habitus özellikleri, renk özellikleri ve çiçeklenme zamanları gibi belirleyici peyzaj özellikleri Tablo 2'de verilmiştir. 


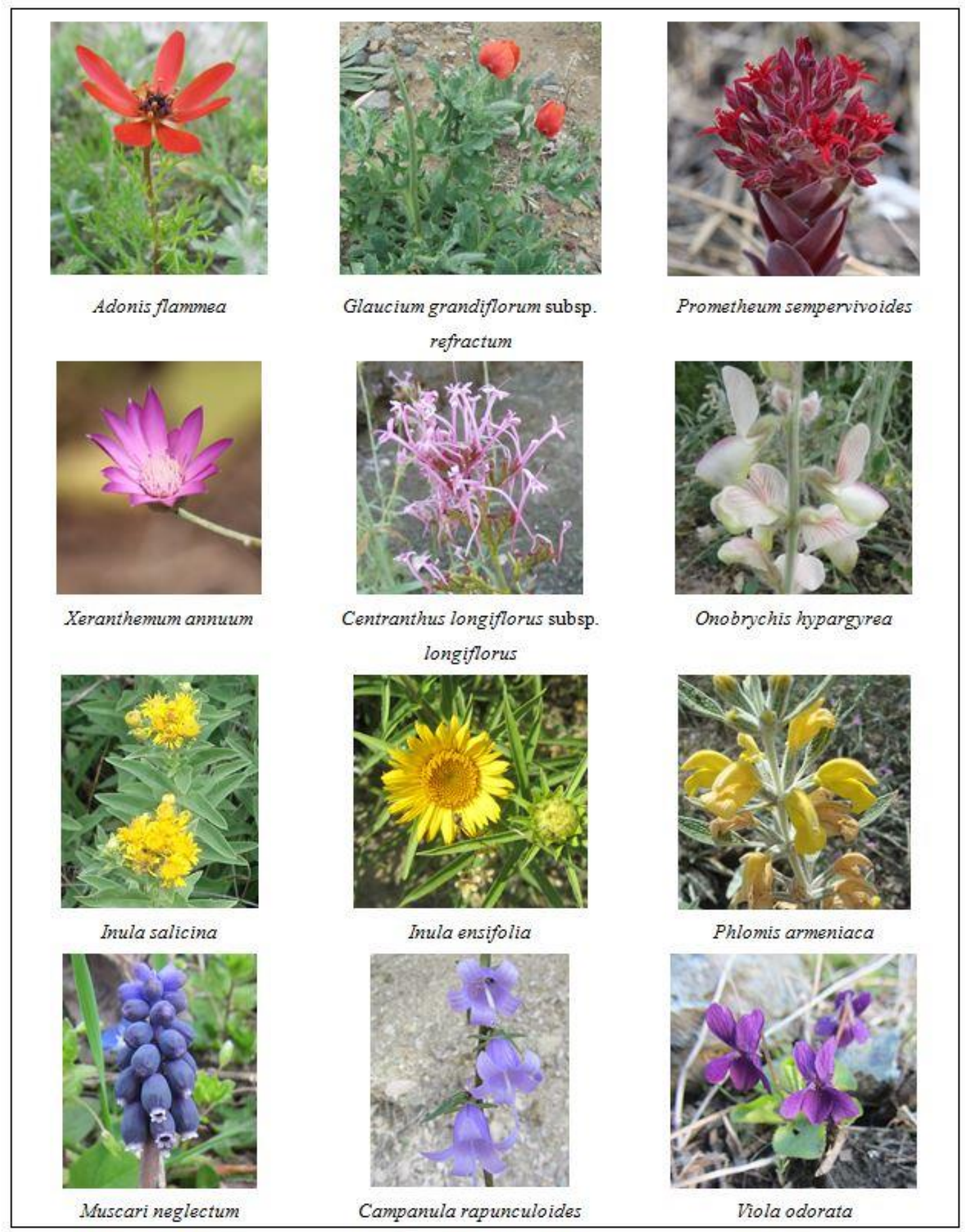

Şekil 2. Çankırı ilinin doğal bazı otsu bitkileri (Orijinal) 
Tablo 1. Otsu bitki türlerine ait botanik özellikler

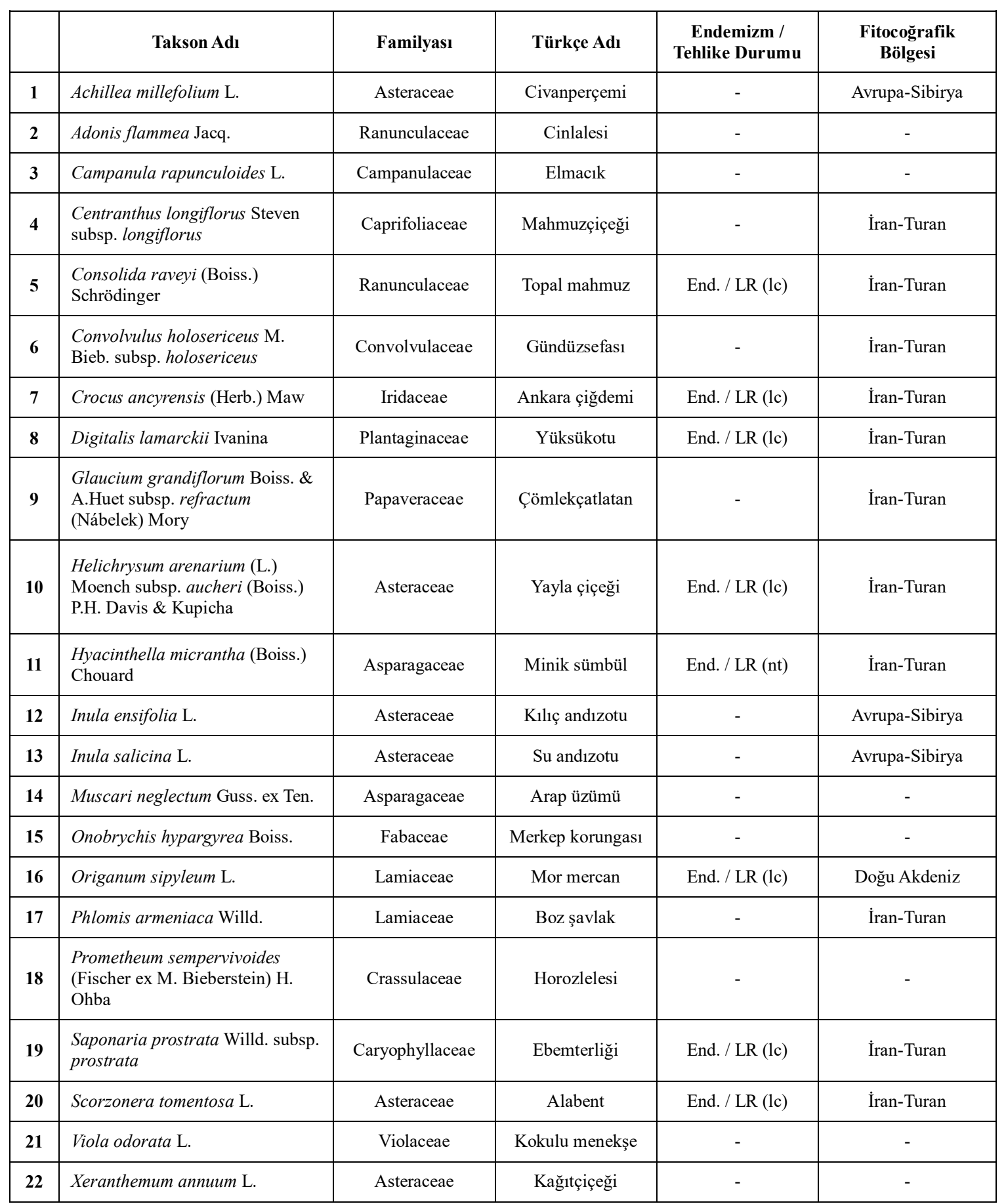

LR (lc): Az tehdit altında, LR (nt): Tehdit altına girebilir 
International Journal of Scientific and Technological Research

ISSN 2422-8702 (Online), DOI: 10.7176/JSTR/5-3-16

Vol.5, No.3, 2019

www.iiste.org

IISE

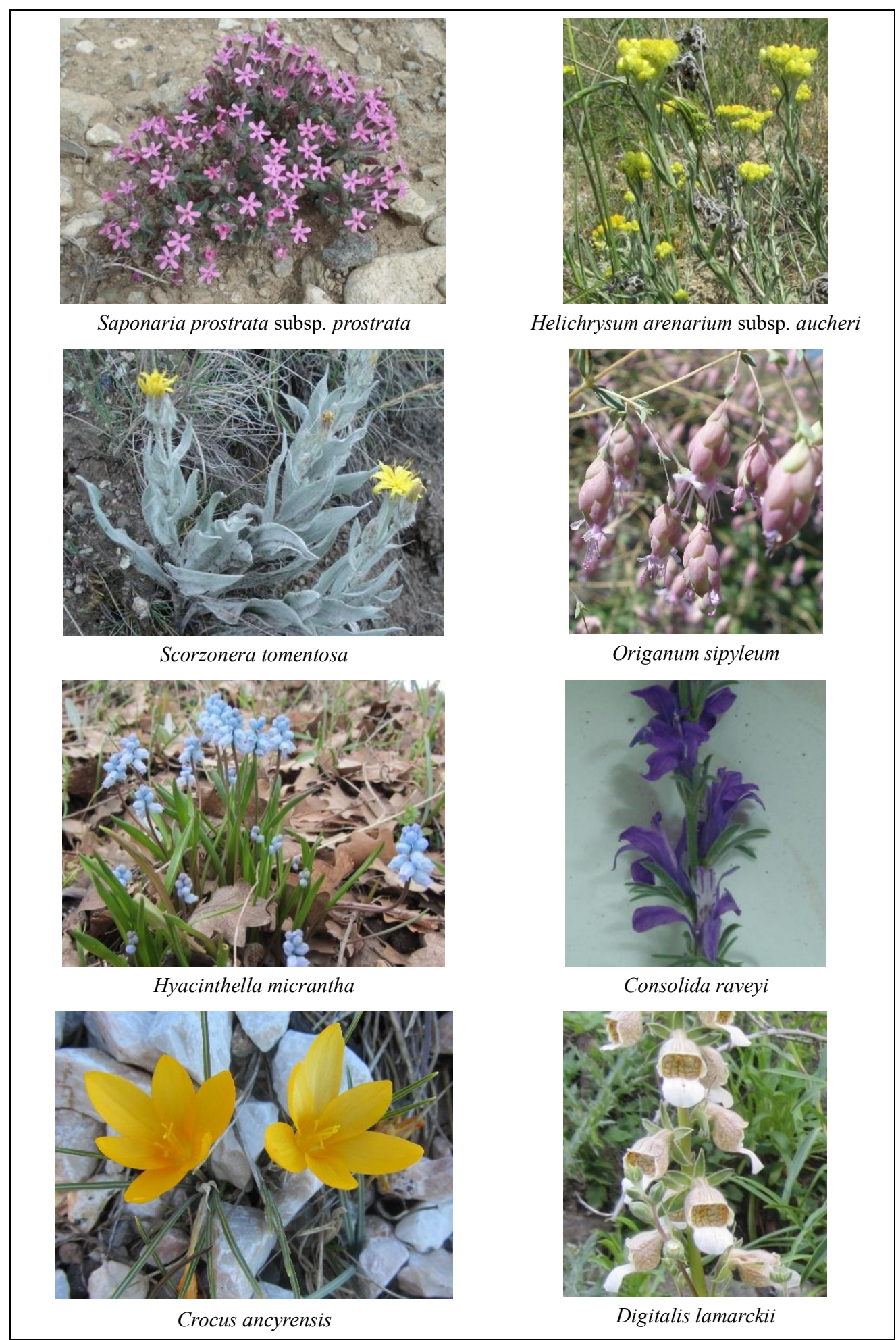

Şekil 3. Çankırı ilinin endemik otsu bitki türleri (Orijinal) 
Tablo 2. Otsu bitki türlerine ait belirleyici bazı peyzaj özellikleri

\begin{tabular}{|c|c|c|c|c|c|}
\hline & Takson Adı & $\begin{array}{l}\text { Boyu } \\
\text { (cm.) }\end{array}$ & Form/Habitus Özelliği & $\begin{array}{c}\text { Renk (çiçek, } \\
\text { yaprak, meyve) } \\
\text { Özelliği } \\
\end{array}$ & $\begin{array}{l}\text { Çiçeklenme } \\
\text { Zamanı }\end{array}$ \\
\hline 1 & Achillea millefolium $\mathrm{L}$. & $10-100$ & Dağınık-dikey form & Bol beyaz çiçek & $6-9$ \\
\hline 2 & Adonis flammea Jacq. & $10-40$ & Dağınık-dikey form & Koyu kırmızı çiçek & $4-6$ \\
\hline 3 & Campanula rapunculoides $\mathrm{L}$. & $30-100$ & $\begin{array}{l}\text { Zarif dikey-kısmen dağınık } \\
\text { form }\end{array}$ & Mor sıralı çiçek & $7-8$ \\
\hline 4 & $\begin{array}{l}\text { Centranthus longiflorus Steven } \\
\text { subsp. longiflorus }\end{array}$ & $70-200$ & Dikey kısmen kompakt form & Bol pembe çiçek & $4-9$ \\
\hline 5 & $\begin{array}{l}\text { Consolida raveyi (Boiss.) } \\
\text { Schrödinger }\end{array}$ & $10-40$ & Düzgün-dikey form & Mor çiçek & $6-7$ \\
\hline 6 & $\begin{array}{l}\text { Convolvulus holosericeus M. Bieb. } \\
\text { subsp. holosericeus }\end{array}$ & -- & Yayılıcı form & Büyük beyaz çiçek & $5-7$ \\
\hline 7 & Crocus ancyrensis (Herb.) Maw & $5-15$ & $\begin{array}{l}\text { Düzgün-dikey kısmen } \\
\text { kompakt form }\end{array}$ & $\begin{array}{l}\text { Bol ve etkili sarı } \\
\text { çiçek }\end{array}$ & $2-4$ \\
\hline 8 & Digitalis lamarckii Ivanina & $25-80$ & Düzgün-dikey form & Beyazımsı-sarı çiçek & $5-8$ \\
\hline 9 & $\begin{array}{l}\text { Glaucium grandiflorum Boiss. \& } \\
\text { A.Huet subsp. refractum (Nábelek) } \\
\text { Mory }\end{array}$ & $0-40$ & Dağınık-dikey form & $\begin{array}{l}\text { Sarı, turuncu, } \\
\text { kırmızı çiçek }\end{array}$ & $6-7$ \\
\hline 10 & $\begin{array}{l}\text { Helichrysum arenarium (L.) } \\
\text { Moench subsp. aucheri (Boiss.) } \\
\text { P.H. Davis \& Kupicha }\end{array}$ & $9-46$ & Düzgün-dikey form & $\begin{array}{l}\text { Parlak sarı çiçek, } \\
\text { Gümüşi-yeşil yaprak }\end{array}$ & $5-8$ \\
\hline 11 & $\begin{array}{l}\text { Hyacinthella micrantha (Boiss.) } \\
\text { Chouard }\end{array}$ & $5-11$ & Dikey form & Açık mavi çiçek & $3-5$ \\
\hline 12 & Inula ensifolia $\mathrm{L}$. & $30-50$ & Yayilıcı form & Büyük sarı çiçek & $5-9$ \\
\hline 13 & Inula salicina $\mathrm{L}$. & $30-60$ & Düzgün-dikey form & Etkili sarı çiçek & $5-9$ \\
\hline 14 & Muscari neglectum Guss. ex Ten. & $10-15$ & Dikey form & Mor çiçek & $3-5$ \\
\hline 15 & Onobrychis hypargyrea Boiss. & $0-50$ & Düzgün-dikey form & $\begin{array}{l}\text { Bol beyaz-pembe } \\
\text { damarlı çiçek }\end{array}$ & $4-6$ \\
\hline 16 & Origanum sipyleum L. & $0-80$ & $\begin{array}{l}\text { Zarif dikey-kısmen dağınık } \\
\text { form }\end{array}$ & $\begin{array}{l}\text { Beyazımsı-morumsu } \\
\text { yoğun çiçek }\end{array}$ & $6-8$ \\
\hline 17 & Phlomis armeniaca Willd. & $0-60$ & Dağınık-dikey form & Bol sarı çiçek & $6-8$ \\
\hline 18 & $\begin{array}{l}\text { Prometheum sempervivoides } \\
\text { (Fischer ex M. Bieberstein) H. } \\
\text { Ohba }\end{array}$ & $7-20$ & Düzgün-dikey form & Koyu kırmızı çiçek & $6-8$ \\
\hline 19 & $\begin{array}{l}\text { Saponaria prostrata Willd. subsp. } \\
\text { prostrata }\end{array}$ & -- & Yayilıci-Kompakt form & Bol pembe çiçek & $4-7$ \\
\hline 20 & Scorzonera tomentosa $\mathrm{L}$. & $19-40$ & Dolgun-dağınık-dikey form & $\begin{array}{l}\text { Büyük, etkili } \\
\text { gümüşi-yeşil yaprak }\end{array}$ & $6-8$ \\
\hline 21 & Viola odorata $\mathrm{L}$. & $3-12$ & Dolgun-dağınık form & Mor çiçek & $4-5$ \\
\hline 22 & Xeranthemum аппиит L. & $5-60$ & Dolgun-dağınık-dikey form & Bol pembe çiçek & $6-9$ \\
\hline
\end{tabular}


Doğal otsu bitki türlerinin belirleyici peyzaj özellikleri ve habitat özelliklerine bağlı olarak saptanan peyzaj uygulamalarında kullanım olanakları ise Tablo 3'te verilmiştir.

Tablo 3. Otsu bitki türlerinin habitat özelliklerine göre peyzajda kullanılma olanakları

\begin{tabular}{|c|c|c|c|}
\hline & Takson Adı & Habitat (yaşam ortamı) Özellikleri & Peyzajda Kullanım Olanakları \\
\hline 1 & Achillea millefolium $\mathrm{L}$. & Dağ çayırlıkları & $\begin{array}{l}\text { Yol kenarında sıra halinde, öbek halinde, } \\
\text { arka fon oluşturmada, çiçek } \\
\text { düzenlemelerinde kuru çiçek olarak }\end{array}$ \\
\hline 2 & Adonis flammea Jacq. & Tarlalar, bozkır, kayalık yerler & $\begin{array}{l}\text { Kaya bahçeleri, parterler, saksılar, öbek } \\
\text { halde kullanım }\end{array}$ \\
\hline 3 & Campanula rapunculoides $\mathrm{L}$. & Kireçtaşı kayalıklar, Picea ormanları & $\begin{array}{l}\text { Çimde grup ya da yol kenarında sıralı } \\
\text { halde, su kenarında }\end{array}$ \\
\hline 4 & $\begin{array}{l}\text { Centranthus longiflorus Steven } \\
\text { subsp. longiflorus }\end{array}$ & Yamaç molozları, kayalık yamaçlar & $\begin{array}{l}\text { Kaya bahçeleri, çim alanda soliter ya da } \\
\text { grup halinde, arka fon oluşturmada, } \\
\text { şevlerde, yamaçlarda }\end{array}$ \\
\hline 5 & $\begin{array}{l}\text { Consolida raveyi (Boiss.) } \\
\text { Schrödinger }\end{array}$ & Bozkır, taşlık alanlar, tarlalar & $\begin{array}{l}\text { Kaya bahçeleri, şevler, parterler, } \\
\text { saksılar, öbek halde kullanım }\end{array}$ \\
\hline 6 & $\begin{array}{l}\text { Convolvulus holosericeus M. Bieb. } \\
\text { subsp. holosericeus }\end{array}$ & $\begin{array}{l}\text { Pinus brutia ormanları, kuru bozkır, } \\
\text { kumlu, kayalık, aşınmış, kil ve } \\
\text { kalkerli tepeler, kireçli alanlar }\end{array}$ & $\begin{array}{l}\text { Kaya bahçeleri, saksılar, öbek halinde, } \\
\text { çimde grup halinde, şevlerde }\end{array}$ \\
\hline 7 & Crocus ancyrensis (Herb.) Maw & Açık kayalık yerler, Pinus ormanları & $\begin{array}{l}\text { Kaya bahçeleri, saksılar, öbek halinde } \\
\text { ve yol kenarında sıra halinde, su } \\
\text { kenarlarında, soğanlı bitki bahçelerinde }\end{array}$ \\
\hline 8 & Digitalis lamarckii Ivanina & $\begin{array}{l}\text { Pinus ya da Quercus orman örtüsü, } \\
\text { kayalık ya da gölgeli yamaçlar, bozkır }\end{array}$ & $\begin{array}{l}\text { Kaya bahçeleri yada yamaçlarda, } \\
\text { şevlerde, çimde grup halinde ya da yol } \\
\text { kenarında sıra halinde, arka fon } \\
\text { oluşturmada }\end{array}$ \\
\hline 9 & $\begin{array}{l}\text { Glaucium grandiflorum Boiss. \& } \\
\text { A.Huet subsp. refractum (Nábelek) } \\
\text { Mory }\end{array}$ & Step alanları ve tarlalar & $\begin{array}{l}\text { Kaya bahçeleri, parterler, öbek halde } \\
\text { kullanım }\end{array}$ \\
\hline 10 & $\begin{array}{l}\text { Helichrysum arenarium (L.) } \\
\text { Moench subsp. aucheri (Boiss.) } \\
\text { P.H. Davis \& Kupicha }\end{array}$ & $\begin{array}{l}\text { Kuru, kalkerli veya kumlu topraklar; } \\
\text { bozkır, kum-toprak yığınları }\end{array}$ & $\begin{array}{l}\text { Kaya bahçeleri, yapay tepeler ve } \\
\text { şevlerde, çiçek düzenlemelerinde kuru } \\
\text { çiçek olarak }\end{array}$ \\
\hline 11 & $\begin{array}{l}\text { Hyacinthella micrantha (Boiss.) } \\
\text { Chouard }\end{array}$ & Kireçtaşı, açık taşlık alanlar, yamaçlar & $\begin{array}{l}\text { Kaya bahçeleri, şevlerde, saksılar, çiçek } \\
\text { parterlerinde sı öbek halinde }\end{array}$ \\
\hline 12 & Inula ensifolia $\mathrm{L}$. & $\begin{array}{l}\text { Akarsular ve çalılar arasında nemli } \\
\text { topraklar }\end{array}$ & $\begin{array}{l}\text { Kaya bahçeleri, saksılar, öbek halinde, } \\
\text { su kenarında ya da süs havuzu } \\
\text { kenarlarında, nemli şevlerde, nemli } \\
\text { yamaçlarda }\end{array}$ \\
\hline 13 & Inula salicina $\mathrm{L}$. & $\begin{array}{l}\text { Akarsular ve çalılar arasında nemli } \\
\text { topraklar }\end{array}$ & $\begin{array}{l}\text { Çim alanda grup halinde ya da sıra } \\
\text { halinde, su kenarında ya da süs havuzu } \\
\text { kenarlarında }\end{array}$ \\
\hline 14 & Muscari neglectum Guss. ex Ten. & $\begin{array}{l}\text { Pinus ormanları, maki, çayırlar, } \\
\text { kayalık kireçtaşı yamaçlar, nadiren } \\
\text { kıyı kumu üzeri }\end{array}$ & $\begin{array}{l}\text { Kaya bahçeleri, saksılar, çiçek } \\
\text { parterlerinde sık öbek halinde, su } \\
\text { kıyısında, soğanlı bitki bahçelerinde }\end{array}$ \\
\hline 15 & Onobrychis hypargyrea Boiss. & $\begin{array}{l}\text { Kayalık yamaçlar, genellikle kireçtaşı } \\
\text { sahaları, nadas alanları }\end{array}$ & $\begin{array}{l}\text { Grup ya da sıra halinde çimde ya da yol } \\
\text { kenarlarında, şevlerde }\end{array}$ \\
\hline 16 & Origanum sipyleum $\mathrm{L}$. & $\begin{array}{l}\text { Kalkerli kayaçlar ve eğimli alanlar, } \\
\text { Pinus ormanları, Quercus makisi, } \\
\text { bozkır }\end{array}$ & $\begin{array}{l}\text { Kaya bahçelerinde, şevlerde, çiçek } \\
\text { parterlerinde, çimde grup-öbek halinde } \\
\text { ya da yol kenarında sıralı halde }\end{array}$ \\
\hline
\end{tabular}


Tablo 3. Otsu bitki türlerinin habitat özelliklerine göre peyzajda kullanılma olanakları (Devam)

\begin{tabular}{|c|c|c|c|}
\hline & Takson Adı & Habitat (yaşam ortamı) Özellikleri & Peyzajda Kullanım Olanakları \\
\hline 17 & Phlomis armeniaca Willd. & $\begin{array}{l}\text { Pinus ormanları, bozkır, kuru kalker } \\
\text { kayaları, mısır ve nadas alanları }\end{array}$ & $\begin{array}{l}\text { Kaya bahçeleri, saksılar, çimde öbek- } \\
\text { grup halinde }\end{array}$ \\
\hline 18 & $\begin{array}{l}\text { Prometheum sempervivoides } \\
\text { (Fischer ex M. Bieberstein) H. } \\
\text { Ohba }\end{array}$ & Kayalık yamaçlar, yamaç molozu & $\begin{array}{l}\text { Kaya bahçeleri, su kıyılarında, saksılar, } \\
\text { çakıl üzerinde }\end{array}$ \\
\hline 19 & $\begin{array}{l}\text { Saponaria prostrata Willd. subsp. } \\
\text { prostrata }\end{array}$ & Tarlalar, tahrip edilmiş sahalar & $\begin{array}{l}\text { Kaya bahçeleri, şevlerde, saksılar, çiçek } \\
\text { parterlerinde, öbek halinde, çakıl } \\
\text { üzerinde }\end{array}$ \\
\hline 20 & Scorzonera tomentosa $\mathrm{L}$. & $\begin{array}{l}\text { Verimli topraklar, step, jipsli tepe } \\
\text { yamaçları, serpantinli tepe yamaçları }\end{array}$ & $\begin{array}{l}\text { Şevlerde-yamaçlarda, } \\
\text { kaya bahçelerinde, çakı1 üzerinde }\end{array}$ \\
\hline 21 & Viola odorata L. & Genellikle gölgeli yerler & $\begin{array}{l}\text { Nemli kaya bahçelerinde, su kenarında, } \\
\text { ağaç altı gölge alanlarda }\end{array}$ \\
\hline 22 & Xeranthemum annuum $\mathrm{L}$. & $\begin{array}{l}\text { Bozkırlar, kurak bayırlar, kumullardaki } \\
\text { durgun su birikintileri }\end{array}$ & $\begin{array}{l}\text { Çiçek parterleri, saksılar, yol kenarı } \\
\text { mevsimlik uygulamaları, öbek halde } \\
\text { kullanım, şevler, kurakçıl peyzaj } \\
\text { uygulamaları, çiçek düzenlemelerinde } \\
\text { kuru çiçek olarak }\end{array}$ \\
\hline
\end{tabular}

Doğal otsu türlerin peyzaj özellikleri ve uygulamalarda kullanımlarına yönelik yapılan değerlendirmeler, bazı akademik çalışmalarla karşılaştırıldığında genellikle benzer özelliklere sahip oldukları tespit edilmiştir. Vural vd.'ne (1996) göre; erozyonlu yamaçlarda görülen Helichrysum arenarium subsp. aucheri türü peyzaj özelliği bakımından yoğun tüylü yapraklara ve kuruduğunda kalıcı kağıtsı hal alan parlak sarı çiçeklere sahiptir. Çalışmada Glaucium grandiflorum subsp. refractum türünün kaya bahçelerinde, parterlerde, öbek halde kullanımı uygun görülürken, Özyavuz'un (2011) çalışmasında ise aynı cinsin bir başka türünün (Glaucium flavum) bordürlerde ve kumluk alanlarda grup halinde ya da yer örtücü olarak kullanımı ve xeriscape bahçelerinde kitle halinde kullanımı önerilmiştir. Araştırmada Muscari neglectum türünün kaya bahçelerinde, saksılarda, çiçek parterlerinde sık öbek halinde, su kıyısında kullanımı önerilirken, Karahan'ın (1998) ve Özyavuz'un (2011) çalışmalarında aynı cinsin farklı bir türünün (Muscari armeniacum) benzer şekilde kaya bahçelerinde, bordürlerde, çiçek parterlerinde, çatıteras bahçelerinde, saksıda ve sınırlayıcı olarak kullanımı önerilmiştir. Karahan (1998) ve Yılmaz ve Karahan (1999) çalışmalarında; Centranthus longiflorus subsp. longiflorus türü için bu çalışmayla benzer şekilde yol şevlerinde kullanımı önermiş, buna karşın çalışmadan farklı olarak Achillea millefolium ve Campanula rapunculoides türleri için çiçek parterleri ve bitki kasalarında kullanımı, Saponaria prostrata subsp. prostrata için çimlere alternatif yerörtücü olarak kullanımı ve Xeranthemum annuum için kaya ve kuru duvar bahçelerinde kullanımı uygun görmüştür. Bu çalışmadan farklı olarak Yılmaz'ın (2006) çalışmasında; Achillea millefolium için su bahçesi kullanımı, Campanula rapunculoides için peyzaj onarım çalışmalarında ve çatı-teras bahçelerinde kullanımı, Centranthus longiflorus subsp. longiflorus için peyzaj onarım çalışmalarında, yerörtücü olarak ve çatıteras bahçelerinde kullanımı, Xeranthemum annuum için peyzaj onarım çalışmalarında ve kaya-kuru duvar bahçelerinde kullanımı önerilmiştir.

\section{Sonuç ve Öneriler}

Bu çalışmada 22 doğal otsu bitkinin kırsal ve kentsel alanlardaki peyzaj uygulamalarında kullanılabileceği sonucuna varılmıştır. Türkiye'de kentsel ve kırsal peyzaj düzenlemelerinde egzotik türlere olan yoğun talep, doğal bitki türlerinin etkin şekilde kullanımını kısıtlamaktadır. Ülkede doğal tür zenginliği yüksek olmasına rağmen, bu türlerin peyzajda kullanımı noktasında yetersiz kalındığı, yapılan birçok akademik çalışmada (Kelkit, 2002; Yılmaz ve Irmak, 2004; Önder ve Akbulut, 2011) ifade edilmiştir. Bitkisel uygulamalarda ekolojik, işlevsel ve ekonomik yönden optimum faydanın sağlanması ancak yerli türlerin tercihiyle mümkün olabilmektedir (Uzun, 1991; Yılmaz, 2006). Özellikle ithal süs bitkilerinin maliyetlerinin son yıllarda yaşanan ekonomik sorunlarla birlikte katlanarak artması, kentlerde doğal türlerin kullanımını zorunlu hale getirmiştir. Ayrıca, yapılan bazı araştırmalarda (Altınçekiç, 1998; Ekici, 2005) doğal türlerin minimum bakım masrafina ihtiyaç duyması ve işgücünden tasarruf sağlaması gibi ekonomik yönden birçok avantajlarının olduğu belirtilmiştir.

Küresel iklim değişikliği ve buna bağlı yaşanması beklenen yoğun kuraklık nedeniyle tüm dünyada su tüketiminin

144 | P a g e

www.iiste.org 
azaltılması yönünde uygulamaların yürütüldüğ̈̈ görülmektedir. Topraklarındaki tuzluluk, kuraklık ve bitki örtüsündeki zayıflık gibi nedenlerle su problemiyle karşı karşıya olan Çankırı ise, suyun akılcı kullanımı bakımından peyzaj alanlarında doğal tür kullanımına öncelik verilmesi gereken illerin başında gelmektedir. Kent genelinde olumsuz çevre koşullarına karşı direnç gösterebilen ve ortama kolayca adapte olabilen yerel türlerin tercih edilmesi (Erduran ve Günal, 2012) yoluyla kent içi ve dışı doğal ortamların oluşturulması, korunması ve iyileştirilmesi sağlanabilecektir. Ayrıca, bitkisel tasarımlarda doğal türlerin kullanımıyla birlikte, hem yabancı türler ile kültüre alınmış türlerden meydana gelen bitki kompozisyonlarının monotonluğu kırılabilecek hem de kentin görsel peyzaj kalitesinin artırılması yoluyla kentsel mekânlar aktif bir biçimde kullanılabilecektir.

Doğal alanlarda görülen habitat parçalanmaları yaban hayvanlarının barınma, beslenme ve üreme gereksinimlerini zora sokmakta ve biyoçeşitliliğin zenginleşmesine imkân vermemektedir. $\mathrm{Bu}$ nedenle, türlerin yaşamsal ihtiyaçlarının karşılanmasına destek olan ve farklı habitat lekeleri arasında bir geçiş görevi gören yaban hayatı koridorlarının oluşturulması açısından, kırsal ve kentsel alanlardaki peyzaj koruma, onarım ve restorasyon çalışmalarında yerel bitki türleri tercih edilmelidir. Çalışmada ortaya konulan peyzaj değeri yüksek türlerin koruma altına alınarak ya da ıslah çalışmaları yapılması yoluyla ülke genelinde üretiminin artırılması gerekmektedir. Doğal türlerin sera ve çeşitli fidanlıklarda kamu ya da özel kuruluşlarca üretiminin yapılması ve geliştirilmesi sonucu yöredeki tür zenginliğinin artırılması söz konusu olabilir.

\section{Kaynaklar}

Acar, C. (1997). Trabzon ve çevresinde yetişen doğal bazı yer örtücü bitkilerin peyzaj mimarlığında değerlendirilmeleri üzerine bir araştırma, Doktora Tezi, Karadeniz Teknik Üniversitesi, Fen Bilimleri Enstitüsü, Trabzon.

Altan, T. (2000). Doğal Bitki Örtüsü. Ç.Ü. Ziraat Fakültesi Genel Yayın No: 235 Ders Kitapları Yayın No: A76, 200 s., Adana.

Altınçekiç, H. (1998). Çilingoz koyu doğal bitki örtüsünde bulunan bazı otsu bitkilerin saptanması ve peyzaj planlamasında değerlendirme olanakları. Kasnak Meşesi ve Türkiye Florası Sempozyumu, 21-23 Eylül 1998, İstanbul.

Anonim. (2010). Çankırı İl Çevre Durum Raporu. T.C. Çankırı Valiliği İl Çevre ve Orman Müdürlüğü, 279 s., Çankırı.

Barış, M.E. (2002). Yeşil alan uygulamalarında doğal bitki örtüsünden yeterince yararlanıyor muyuz?. II. Ulusal Süs Bitkileri Kongresi,. s: 91-95, Antalya.

Beninde, J., Veith, M., Hochkirch, A. (2015). Biodiversity in cities needs space: A meta-analysis of factors determining intra-urban biodiversity variation. Ecology Letters 18: 581-592.

Booth, N. (1990). Basic elements of landscape architectural design. Waveland Pres, Inc Illinois, USA.

Cengiz, B. (2001). Batı Karadeniz Bölgesi Doğal Bitki Örtüsünde Peyzaj Uygulamaları Amacına Yönelik Bazı Creataegus L. Taksonlarının Saptanması. (Basılmamış Yüksek Lisans Tezi), Zonguldak Karaelmas Üniversitesi, Fen Bilimleri Enstitüsü, S:122, Bartın.

Chan, L., Hillel, O., Elmqvist, T., Werner, P., Holman, N., Mader, A. and Calcaterra, E. (2014). User's Manual on the Singapore Index on Cities' Biodiversity (also known as the City Biodiversity Index). Singapore: National Parks Board, Singapore. ISBN: 978-981-07-8816-2.

Davis, P.H. (1965 - 1988). Flora of Turkey and East Aegean Islands. Vol. I - XI, Edinburg.

Dilaver, Z. (2001). Ayaş Beli ve Çevresi Doğal Bitki Örtüsü Örneklerinin Peyzaj Mimarlığı Çalışmalarında Kullanılabilirliğinin Değerlendirilmesi Üzerine Bir Araştırma, Doktora Tezi, Ankara Üniversitesi, Fen Bilimleri Enstitüsü, Peyzaj Mimarlığı Anabilim Dalı, Ankara. 
Dilaver, Z. (2014). Dilaver, Z. 2014. İç Anadolu Doğal Bitki Örtüsü Örneklerinden Peyzaj Mimarlığında Yararlanma. İklim Değişikliğine Yerel Çözümler: Doğal Bitki Örtüsüyle Sürdürülebilir Uygulamalar, Doğal Bitkilerle İklim Dostu Çankaya Parkları Projesi Eğitim Kitapçı̆̆ı, Peyzaj Araştırmaları Derneği, Ankara.

Doğan, U. (2002). Çankırı Doğusunda Jips Karstlaşmasıyla Oluşan Sübsidans Dolinleri, G.Ü. Gazi Eğitim Fakültesi Dergisi, 22 (1), 67-82.

Ekici, B. (2005). Batı Karadeniz Bölgesi Peyzaj Düzenlemelerinde Kullanılan Bazı Doğal Ve Egzotik Bitkiler. Zonguldak Karaelmas Üniversitesi, Fen Bilimleri Enstitüsü, Orman Mühendisliği Anabilim Dalı Yüksek Lisans Tezi, 221 s., Zonguldak.

Erduran, F. \& Günal, İ. (2012). Manisa, Soma ilçesi yeşil alanlarında kullanılan tasarım bitkilerinin belirlenmesi ve doğal bitki örtüsünden yararlanma olanakları. Selçuk Tarım ve Gıda Bilimleri Dergisi, 26 (1): $1-10$.

Gökmen, B. (2007). Çankırı ili coğrafyası. Doktora tezi. Ankara Üniversitesi, 369 s., Ankara.

Güner, A., Akyıldırım, B., Alkayış, M. F. Çıngay B., Kanoğlu, S.S., Özkan, A.M., Öztekin, M., Tuğ, G.N. (2012). Türkçe bitki adları. Şu eserde: Güner, A., Aslan, S. Ekim, T. Vural, M. \& Babaç, M.T. (edlr.). Türkiye Bitkileri Listesi (Damarlı Bitkiler). Nezahat Gökyiğit Botanik Bahçesi Yayınları, Flora Dizisi:1, İstanbul.

IUCN. (2013). About biodiversity. http://www.iucn.org/what/biodiversity/about/ [14.02.2019].

Karahan, F. (1998). Erzurum ve Yakın Çevresi Alpin Vejetasyonunda Yer Alan Bazı Bitkilerin peyzaj Mimarlı̆̆ı Çalışmalarında Kullanım Olanakları Üzerine Bir Araştırma. Atatürk Üniv. Fen Bilimleri Enst. Peyzaj Mimarlığı Anabilim Dalı Yüksek Lisans Tezi, Erzurum, s 116.

Kelkit, A. (2002). Çanakkale kenti açık-yeşil alanlarında kullanılan bitki materyali üzerinde bir araştırma. Ekoloji, 10(43): 17-21.

Önder, S. \& Akbulut, Ç.D. (2011). Kentsel açık-yeşil alanlarda kullanılan bitki materyalinin değerlendirilmesi; Aksaray kenti örneği. Selçuk Tarım ve Gıda Bilimleri Dergisi, 25 (2): 93-100, Konya.

Özyavuz, A. (2011). Tekirdağ (Kumbağ-Şarköy Arası) Kıyı Şeridindeki Doğal Örtüde Bulunan Bazı Bitkilerin Saptanması Ve Peyzaj Mimarlığında Kullanım Olanakları. Namık Kemal Üniversitesi Fen Bilimleri Enstitüsü Yüksek Lisans Tezi, 92 sayfa, Tekirdağ.

Tuna, F. (2010). Çankırı'nın coğrafi özelliklerinin şehirsel gelişim potansiyeli yönünden değerlendirilmesi. Marmara Coğrafya Dergisi, 21: 219-239, ISSN:1303-2429.

Tuttu, G. \& Akkemik, Ü. (2017). Çankırı-Korubaşı Tepe ve Civarındaki Jipsli Alanların Florası. Ot Sistematik Botanik Dergisi, 24 (1); 45-88.

http://www.theplantlist.org. [18.02.2019].

Uzun, A. (1991). İstanbul Adalarının Doğal ve Egzotik Bitki Türlerinin Adalar Peyzajındaki Yeri ve Önemi Üzerine Araştırmalar, Doktora Tezi, İ.Ü. Fen Bilimleri Enstitüsü, İstanbul, 195 s.

Vural, M., Kol, Ü., Çopuroğlu, S., Umut, B. (1996). Göreme Milli Parkındaki Bitkilerin Tespiti ve Bunların Peyzaj Mimarisi Yönünden Değerlendirilmesi, Ormancılık Araştırma Enstitüsü Yayınları, No: 263.

Yazgan ME, Korkut AB, Barış E, Erkal S, Yılmaz R, Erken K, Gürsan K, Özyavuz M. (2005). Süs Bitkileri Üretiminde Gelişmeler, Türkiye Ziraat Mühendisliği VI. Teknik Kongresi, 589-607, Ankara. 
Yılmaz, H. (2006). Erzurum-Uzundere Karayolu Şevlerinde Doğal Olarak Yetişen Bitkilerin Estetik ve Fonksiyonel Yönden Değerlendirilmesi. (Basılmamış Yüksek Lisans Tezi), Atatürk Üniversitesi Fen Bilimleri Enstitüsü, Peyzaj Mimarlığı Anabilim Dalı, S: 180, Erzurum.

Yılmaz, H. \& Irmak, M.A. (2004). Erzurum kenti açık-yeşil alanlarında kullanılan bitki materyalinin değerlendirilmesi. Ekoloji, 13(52): 9-16.

Yılmaz, H. \& Karahan, F. (1999). Alpin bitkilerin korunması ve yararlanma olanakları. Atatürk Üniversitesi Ziraat Fakültesi Dergisi, 30 (1):95-103. 